\title{
Cárcel. derechos humanos y encierro
}

\section{Prison. Human Rights, and Imprisonment}

\author{
Alexis Sánchez Vega ${ }^{1}$ \\ Ministerio de Justicia y Paz \\ Costa Rica
}

\section{Resumen}

El actual artículo tiene como objetivo el análisis de los últimos cinco años del Sistema Penitenciario Costarricense, para dejar en evidencia en qué estado se encuentra y cuáles han sido las propuestas de política pública para atender el problema del encarcelamiento de personas y los problemas que se derivan de esta actividad. Se realiza una revisión teórica y metodológica que pueda dar cuentas de la cárcel como institución reformadora y la sobrepoblación penitenciaria. Se considera importante la discusión que se desarrolla al visualizar el papel de la cárcel que se ha instrumentalizado como un mecanismo social al que se le ha dado una justificación que le permite considerarse como una solución para el problema delincuencial del país. A esta se le ha dado el papel de ente resocializador y el lugar "adecuado" para que las personas consideradas como delincuentes puedan cumplir sus penas de prisión. Sin embargo, el advenimiento de las reformas penales y de seguridad ciudadana de principios del siglo veintiuno provocaron el aumento de la población privada de libertad y la aparición de dos fenómenos: la sobrepoblación y el hacinamiento. Esto ha ocasionado que ambos elementos vulneren los derechos de las personas encarceladas. Por lo tanto, se presenta una propuesta para reducir los efectos del uso de la cárcel y con ello se mejore la calidad de vida de las personas que se encuentran en reclusión, a partir de una política institucional y política criminal diferentes.

Palabras clave: cárcel; sobrepoblación; hacinamiento; encierro; derechos humanos; personas privadas de libertad.

1 Licenciado en Historia y Magister Scientae en Administración Pública por la Universidad de Costa Rica, es funcionario del Ministerio de Justicia y Paz, profesor de Sociología Criminal en el Colegio Universitario de Cartagose. Se desempeña como Consultor del Instituto latinoamericano de las Naciones Unidas para la Perención del

Delito y Tratamiento del Delincuente. ILANUD. Correo electrónico: alexis@ilanud.or.cr 


\begin{abstract}
This article aims to analyze the last five years of the Costa Rican Penitentiary System, to show in which state it is and what the public policy proposals have been to address the problem of incarceration of persons and the problems derived from this activity. A theoretical and methodological review is carried out to account for prison overpopulation and the prison as a reforming institution. The discussion is considered important when visualizing the role of the prison system, which has been instrumentalized as a social mechanism and given a justification that allows it to be considered as a solution to the country's delinquency problem. Prison has been given the role of the resocializing entity and the "right" place for people considered as criminals to serve their prison penalties. However, the advent of penal and citizen security reforms from the early twenty-first century led to an increase in the population deprived of liberty and the emergence of two phenomena: overpopulation and overcrowding. This has caused both elements to violate the rights of people imprisoned. Therefore, a proposal is presented to reduce the effects of the use of prison and thereby improve the quality of life of people in incarcerated, based on a different institutional and criminal policy.
\end{abstract}

Keywords: prison; overpopulation; overcrowding; imprisonment; human rights; people deprived of liberty.

\title{
I. Introducción
}

Desde mediados del siglo XVIII, se viene hablando en el mundo penitenciario de mantener condiciones mínimas de ubicación y atención de la población penitenciaria. Desde el texto escrito por John Howard, a propósito de la visita que este realizara a las prisiones de Inglaterra y Gales, se ha venido tratando de cumplir, a través de las diferentes ideologías que han dominado el mundo de la gestión penal, con una serie de condiciones mínimas para que la estancia de las personas privadas de libertad en los centros de reclusión sea más favorable y de alguna manera más humana.

También es importante hacer notar que cada ideología penitenciaria desarrollada desde los escritos de J. Howard y, posteriormente de Jeremías Bentham hasta el presente, relacionados con el diseño de las edificaciones carcelarias y su organización, han impuesto la necesidad de separar a dicha población por sexo, edad, condición jurídica y privilegia las condiciones de dignidad de las ubicaciones de estas personas, al considerarlas plausibles de cambio a través del tratamiento de sus conductas. 
Al interior de las prisiones, años después con el advenimiento de nuestra contemporaneidad, las Reglas Mínimas de las Naciones Unidas para Tratamiento del Delincuente de 1955, ( hoy estas reglas se denominan Reglas Nelson Mandela, que son una revisión de las antiguas reglas del año 55 y que se acondicionaron a las nuevas realidades sociales, políticas y de la criminalidad en el mundo) recogieron la herencia de los siglos pasados y establecieron formalmente estas recomendaciones como instrumentos básicos del funcionamiento de los sistemas penitenciarios, en los países que habían adoptado la carta de Naciones Unidas y que habían también incorporado las convenciones que en materia de derechos humanos y dignidad humana se habían promulgado por parte del órgano deliberativo de la organización.

El mundo de lo penitenciario incursiona entonces en una nueva fase, producto de la incorporación de legislación internacional, que afecta las dinámicas y costumbres en el manejo de personas que habían transgredido la ley o habían provocado alguna situación contraria a las libertades y derechos de los demás. La cárcel se institucionaliza y se vuelve el foco de las políticas públicas por parte del Estado.

Las situaciones de violencia y abuso de poder, que en el pasado no eran noticia, ahora se promocionan a través de los medios de comunicación y por medio de organismos de protección de derechos, lo que afecta significativamente a la ética del Estado y la gestión de funcionarios de carrera y de políticos que, por asignación del Estado y las políticas sociales, están compenetrados con el trabajo de las personas que purgan sentencias o esperan una. Entonces, como una acción transformadora se incorpora en el lenguaje y en el pensamiento de los funcionarios de las cárceles los principios de dignidad, derechos humanos y trato justo de las personas en administración.

En este artículo analizaremos los últimos cinco años del Sistema Penitenciario Costarricense, para dejar en evidencia en qué estado de cosas se encuentra y cuales han sido las propuestas de política pública para atender el problema del encarcelamiento de personas y los inconvenientes que se derivan de esta actividad.

\section{La cárcel como institución reformadora}

Después de más de doscientos años de reformas al régimen de privación de libertad, podemos afirmar que la prisión no ha servido al pretendido fin resocializador de la persona como instrumentación de la pena privativa de libertad, según Eugenio Raúl Zaffaroni (1990) "La filosofía del sistema penitenciario en el mundo 
contemporáneo. Conferencia Especial en el seminario regional para Directores de centros penitenciarios y de detención en América Latina."

A esta altura del siglo XXI, sería honesto reconocer que el encierro y la cárcel, como instituciones de castigo no han resuelto el problema para el cual fueron creadas, desde este contexto entonces se utiliza la privación de libertad como un instrumento de control y no de rehabilitación, pues parte del principio de que la privación de libertad permite reducir o eliminar el deseo de transgresión de la ley que tienen los ciudadanos. Esta concepción ha sido considerada desde ya hace mucho tiempo una falacia, o sea que entre más personas sean encerradas menos posibilidades existen para resolver el conflicto social que dio origen al fenómeno de la criminalidad (Hulsman y Bernard de Celis, 1984; García, 2005).

Pero, precisamente en los momentos (nos referimos a los años noventa del siglo pasado) en que se consagraba legalmente y se establecía la orientación de la política penitenciaria del país encaminada hacia el fin resocializador, dos fenómenos importantes hacían su aparición casi conjuntamente:

a) Por un lado, se empezó a hablar de la crisis de la resocialización, sus limitaciones para grupos importantes de delincuentes como los ocasionales. El caso del delincuente ocasional tiene en la criminología un problema importante de definición, en principio porque la conducta desplegada considerada ilegal no es consuetudinaria. Por el contrario, es fortuita y, por ende, no es patológica. En la posición de algunos criminólogos de la reacción social, enviar a prisión a estas personas es solamente la expresión máxima de la venganza.

En el caso de los delincuentes por convicción y los delincuentes socioeconómicos, se llamó la atención sobre la imposibilidad de llevarlos a prisión con la consecuente necesidad de utilizar cantidades importantes de recursos económicos del Estado, lo cual es difícil de solventar en momentos de crisis del Estado de bienestar y, por consiguiente, retraimiento del gasto público, entre otras medidas.

b) Por otro lado, se empieza a configurar una política criminal y también penitenciaria, excepcional para hacer frente al crimen organizado.

Hoy, se puede decir que después del encanto resocializador vivido durante los años setenta y comienzos de los ochenta del siglo pasado, asistimos a una etapa real de retraimiento de los principios de la resocialización en el cumplimiento de penas privativas de libertad. La praxis de asesinatos cometidos por sujetos que gozaban de permisos de salida, la magnificación de la inseguridad ciudadana por 
ciertos medios de comunicación. El aumento de la violencia de las actividades del crimen organizado de los últimos tiempos han propiciado un introversión formal de las orientaciones criminológicas que justificaban la acción resocializadora de la pena de prisión. Esta manifestación quedó ampliamente desarrollada en la justificación del documento denominado Plan de Desarrollo Institucional (PDI), que publicara la Dirección General de Adaptación Social y al cual se le dio un valor de política penitenciaria durante algunos años del fin del siglo pasado. De alguna manera, se renunció al uso de conceptos extraídos de las filosofías sociales relacionadas con los "re" y se consideró explícitamente que el factor rehabilitación y resocialización no eran factibles en la cárcel.

Esto se ha hecho patente con la utilización de otras formas de control y supervisión de las personas que ejecutan penas privativas de libertad, como por ejemplo, las ubicaciones en establecimientos penitenciarios abiertos, en donde se dio la intentona por eliminar la reducción de las penas mediante el trabajo o la educación.

Para el mes de mayo de 1994, se publicó un nuevo texto del artículo 55 del Código Penal. El legislador promovió, a través de este nuevo texto, la extensión del tiempo de control y vigilancia del preso al exponer de forma clara que el descuento de la pena solo sería cierto a partir de la mitad de esta y que los descuentos derivados del trabajo y la educación solo se aplicarían en la segunda mitad de la pena, por lo cual, de manera simbólica se amplió el espacio de control y supervisión del Estado sobre el personal, lo que provocó el aumento del cumplimiento efectivo de las penas en el sitio carcelario. Con esta acción, de alguna manera se hace explícito el deseo de los grupos sociales de poder por mantener al delincuente bajo control y observación, en tanto la pena de prisión no se hubiese agotado en su propósito de encierro y segregación social.

Desde nuestro punto de vista, la sociedad costarricense no estaba interesada en los logros del proceso de tratamiento, sino en el tiempo de ejecución de la pena, o sea, cuánto le falta o cuánto le queda por ejecutar al delincuente. De alguna manera, se establece de forma simbólica un deseo de la sociedad por controlar el cuerpo del delincuente y, por ende, de su conciencia. Sobre este tema, es valiosa la lectura de un clásico de la criminología escrito por Michel Foucault denominado "Vigilar y castigar, El nacimiento de la prisión". En este libro, Foucault elabora la teoría del poder y del control de la sociedad sobre los menos hábiles y, de alguna manera, vislumbra el deseo de controlar el cuerpo y alma de la persona presa.

Indudablemente, existen muchas limitaciones para llevar a cabo el proceso re-insertador de la persona privada de libertad en la sociedad desde la cárcel y quizás, 
es importante conectarlo con dos momentos fundamentales: antes y después del cumplimiento de la pena, esto es, buscar remover y contrarrestar la marginación social y la violencia que la delincuencia conlleva, así como brindar al exprivado de libertad una seria asistencia pospenitenciaria.

Este es un tema poco o casi nada desarrollado en Costa Rica. Los esfuerzos que se realizan son muy aislados y poco sistemáticos, responden a cierto compromiso social de algún funcionario penitenciario, pero no al deseo de una acción de política penitenciaria. También, puede verse Sánchez (2018) “Aciertos y desafíos de los Sistema Penitenciarios en América Latina desde una perspectiva de Derechos Humanos", ponencia que se presentó en el Congreso de Criminología en la Ciudad de Guanajuato, México.

En lo que sí prácticamente todos los autores y organismos de Naciones Unidas están de acuerdo es en que mientras exista la cárcel, esta debe tender por lo menos a hacer del encierro un proceso lo menos segregado posible, que busque evitar el desarraigo social y familiar, de manera que la preparación para la vida en libertad sea un objetivo fundamental del proceso de atención o tratamiento, con el fin de conseguir que el recluso o privado de libertad no recaiga en el delito al salir de la prisión. El Ministerio de Justicia y Paz, a finales de 2017, publicó un documento denominado "Política penitenciaria. Científica y humanista". En este documento se anotó como necesaria una acción pospenitenciaria, organizada y sostenible en el tiempo.

Se sostuvo durante mucho tiempo que el fin resocializador de la pena propiciaba la humanización de las cárceles y, por ende, de la ejecución de la pena. La responsabilidad del logro de esta pretensión recaía en lo individual y en lo social, de manera que este proceso de carácter intercomunicativo procuraba la integración social paulatina del delincuente, con miras a evitar que la pena en su fase de ejecución se convirtiera en un mera venganza o castigo, con claro predominio de la retribución per se. Sin embargo, esto fue teorización de la ejecución de la pena, porque, como veremos más adelante, las cárceles del país se encuentran sobrepobladas y hasta hacinadas.

Durante los últimos ocho años (2010 a 2018), los jueces de ejecución de la pena han dictado "medidas correctivas" para que el Sistema Penitenciario Nacional desarrolle o ejecute instrumentos de humanización de la pena y reduzca el número de residentes en prisión cerrada, dado que las condiciones materiales y humanas de estas no son de recibo de acuerdo con la normativa internacional de derechos humanos. Lo paradójico de este panorama es que en la mayoría de los 
documentos y manifestaciones de los dirigentes de la cárcel simbólicamente exponen su deseo de respetar los derechos humanos y la dignidad de las personas, pero bajo un condicionamiento de seguridad ciudadana, hecho que hace impracticable la desinstitucionalización de personas, de aquellas que no necesitan del control total de sus acciones.

Ahora resulta muy interesante enfrentarse al proceso transformador (al menos eso es lo que sostienen los que participaron en estas actividades) que Costa Rica ha intentado realizar en los últimos treinta años y enumeramos algunos de los hechos que ponen en análisis la incertidumbre del presente en cuanto a la administración de la ejecución de la pena:

a) Para 1993, se abandona el Sistema Progresivo Penitenciario y la Criminología Clínica como enfoque para el tratamiento del delito y de la pena.

b) Se publica el Plan de Desarrollo Institucional y se advierte que la persona privada de libertad es un sujeto de derecho y de obligaciones. Por cierto, este cambio de denominación de preso, reo a persona privada de libertad es en principio un reconocimiento a la humanidad que debe tener la pena.

c) Se advierte, además, que en el plano de la atención (se elimina del lenguaje oral y escrito la palabra tratamiento) el individuo se ve como un ser integral y no como un fraccionamiento disciplinar (Ministerio de Justicia y Gracia, 1993).

d) Se fortalecen las acciones, prácticas y políticas de desinstitucionalización $\mathrm{y}$, por primera vez en el caso de Costa Rica, se habla formalmente de no institucionalización, aunque estas actividades se venían desarrollando de forma adjunta a la desinstitucionalización a través de un programa denominado Prueba y Libertad Vigilada, mediante circular del Instituto Nacional de Criminología desde 1982. Para esta época, la Dirección General de Adaptación Social tenía en funcionamiento una oficina denominada Consulta Externa, que evitaba que algunas personas ejecutaran las penas privativas de libertad en el encierro. Estas eran atendidas en la comunidad y con una vigilancia limitada a una visita a las oficinas del programa de Prueba y Libertad Vigilada o a una delegación de la policía en el medio rural, cuando le era difícil llegar a alguno de los centros u oficinas del programa. Este proyecto se eliminó para mediados de los noventa y se mantuvo así hasta el 2016.

e) Ante la necesidad de evitar que las personas ingresaran a la cárcel con penas menores a cinco años o con sentencias de meses de prisión, el Instituto Nacional de Criminología y la Dirección General de Adaptación Social proponen al despacho de la Ministra de Justicia y Paz un nuevo reglamento 
del Sistema Penitenciario Nacional en donde se norma el funcionamiento de una oficina que logre hacer una realidad la no institucionalización de personas con sentencias que no representan un peligro para la sociedad.

f) Año en el que una nueva forma de interpretar la privación de libertad hace necesaria la revisión de la practica penitenciara que se venía llevando a cabo desde los noventa del siglo pasado.

g) El formato del sistema penitenciario existente provocaba que las personas, independientemente de la sentencia que tuvieran que ejecutar, debían hacerlo en la prisión cerrada. Esto significaba que personas con sentencias menores a cinco años y por delito no significativos en el nivel de la seguridad social tuviesen que estar en prisión al menos un año antes de ser contemplada su sentencia. Esto implicó que personas sin ninguna socialización criminal tenían que pernoctar y compartir al menos un año de la sentencia con personas con una socialización criminal importante, aunque en los documentos oficiales se sostenía la tesis de que las políticas penitenciarias estaban asociadas a disminuir el efecto iatrogénico de la prisión.

h) Ante la falta de una ley de ejecución de penas privativas de libertad para adultos sentenciados en Costa Rica, a un órgano de la administración penitenciaria le ha correspondido elaborar lo que se denomina "Derecho Penitenciario". En este se ha regulado de manera técnica la forma y el lugar para ejecutar las penas establecidas por los tribunales de justicia del país. Si se quiere, este órgano al ser dependiente de una autoridad administrativa y política, puede verse influenciado por posiciones de carácter mediático que podrían afectar las formas administrativas de ejecutar las penas. Esta circunstancia ha provocado que en algunos momentos las políticas de institucionalización se privilegien por encima de las políticas de desinstitucionalización y las cárceles del país se transformen en sitios sobrepoblados o hacinados.

Desde nuestro punto de vista, lo que se intentaba generar no solo era un cambio en el paradigma criminológico, sino el establecimiento de un nuevo enfoque del fenómeno criminal, como un producto de la sociedad costarricense, y que las formas de intervención para la reducción del daño que causaba el delito a la sociedad no podían estar centradas solo en la cárcel o en el castigo y en la estigmatización que produce la pena. Para nuestro entender, esta creencia en la cárcel ha llevado a que la política criminal del Estado costarricense se encuentre en una encrucijada, en donde el encierro es la solución de todos los problemas de la sociedad y la reducción que produce la cárcel de las capacidades delincuenciales de las personas contenidas en ella favorece una convivencia social en paz, aunque las 
instituciones carcelarias mantengan en proceso de crecimiento su población y, por ende, la infraestructura con sobreuso. Desde la ética y la moral de los instrumentos internacionales de derechos humanos, se está en una flagrante violación (Wacquant, 2010).

\section{La sobrepoblación penitenciaria}

El advenimiento del siglo XXI trajo consigo el cambio en la visión del concepto de justicia y se entendió que esta solo se podría lograr con la implementación de medidas coercitivas y la aplicación de la ley penal, de acuerdo con un criterio vindicativo. El crecimiento de la población penitenciaria empieza a ser de importancia en Costa Rica a partir del 2008.

La Corte Suprema de Justicia y el Gobierno de la República, a través de la implementación de políticas de seguridad ciudadana o de seguridad pública, promocionan el crecimiento de:

a) El aparato policial que incluye la contratación de más policías para el Organismo de Investigación Judicial y la contratación sostenida de forma anual de policías de la Fuerza Pública.

b) El crecimiento de los tribunales en país y la contratación de jueces y fiscales.

c) La introducción del pensamiento eficientista en la labor judicial y el nombramiento de administradores en los despachos judiciales para favorecer la disminución del circulante y el aumento de eficiencia de la justicia a través de la emisión de sentencias.

d) La constitución de nuevas formas de control por intermedio de la creación de Tribunales de Flagrancia.

Estos elementos son el inicio del fenómeno de la sobrepoblación penitenciaria, entre otros factores que han sido determinados por varios estudios universitarios como elementos provocadores de la hiperinflación de personas privadas de libertad, en los establecimientos penitenciarios. A este nuevo enfoque de la cuestión criminal se le denomina populismo punitivo, que se encuentra enmarcado en las denominadas corrientes del pensamiento de "ley y orden" o políticas de mano dura (Madrigal, 2012).

Encontramos entonces las siguientes manifestaciones:

- La diabolización del delito, a este factor se le atribuye la manipulación de los delitos en su contenido y magnificación. 
- El uso de estadísticas que hacen pensar a la comunidad que el país se encuentra ante una catástrofe.

- Se victimiza a la sociedad en general, cuando los efectos de los actos criminales denominados violentos solo afectan a una pequeña parte. Este hecho fue ampliamente difundido por autoridades del Organismo de Investigación Criminal cuando utilizaban las estadísticas del comportamiento de los homicidios como un factor de inseguridad ciudadana y una justificación para la solicitud de aumento del presupuesto de esta organización judicial.

- Se expone a la comunidad nacional la necesidad de endurecer las penas o aumentar los castigos y la creación de nuevas conductas criminales, como el involucramiento de figuras de la política nacional en la justificación del encierro como una actividad positiva para reducir la criminalidad.

- Otros elementos explotados por los medios de comunicación escritos y visuales son el manejo indiscriminado de los conceptos de "banda criminal organizada" y de "crimen organizado" lo que genera confusión y alarma en la colectividad nacional. Esta se fomenta en el momento que se declara a los aparatos del subsistema de justicia penal encargados del control policial como inadecuados y retardatarios en provocar soluciones.

Una vez establecidos los factores que dan origen al crecimiento de la población penitenciaria, iniciemos por analizar qué significados tienen estos conceptos en materia de dicha política. Con la aplicación de medidas "eficientistas" en el aparato policial y el judicial, en el nivel penitenciario se empiezan a observar situaciones como "amontonamiento de personas en el sistema carcelario, considerado excesivo en relación con la capacidad máxima de los establecimientos penitenciarios", o también, se puede definir como "resultado de una política criminal que procura privar de libertad a más personas". Nuestra población privada de libertad ha aumentado y su incremento ha sido de tal magnitud que la Administración Penitenciaria no ha tenido la capacidad de ampliar en igual medida los espacios carcelarios (Robles, 2012).

Cuando hablamos de sobrepoblación y de hacinamiento penitenciario, nos introducimos en una problemática de derechos humanos y específicamente de dignidad humana, de hecho, la literatura como las manifestaciones de los jueces de ejecución de la pena, han declarado que esta situación provoca los siguientes problemas:

- Vulneración del derecho a la vida y a la integridad física.

- Vulneración al derecho a la salud.

- Vulneración de los fines declarados de la pena.

- Vulneración del derecho a comunicación con el exterior. 
En el primero de los casos mencionados por el crecimiento desmedido de la población y por la incapacidad del sistema penitenciario de proveer nuevos espacios, esta circunstancia se vuelve un factor de violencia por la aglomeración de personas y provoca también la comisión de nuevos delitos por parte de las personas recluidas. Asociado a los problemas interpersonales y de seguridad de la población, la pérdida de control interno estimula el tráfico de drogas entre la población. Otro fenómeno que se deriva de la sobrepoblación o del hacinamiento es la pérdida de la calidad en cuanto a la atención en salud y las reglas de saneamiento ambiental, que se ven afectadas de forma singular (Sanchez, 2011; Tidball-Binz, 2001).

Se debe mencionar que el incremento de personas privadas de libertad significa el crecimiento en los gastos no estimados del presupuesto general en el sistema penitenciario, lo que provoca una baja en la calidad del suministro de alimentos, en su variedad y, por supuesto, se debe incluir en este análisis la reducción en los servicios generales por falta de financiamiento o contenido económico. Otro elemento que es meritorio de analizar es el hecho de que los servicios de atención profesional también se ven afectados, debido a que las demandas de atención de las necesidades primarias de la población penitenciaria no se logran satisfacer adecuadamente, los procesos de acercamiento familiar se retrasan, así como el vínculo íntimo; por consiguiente, se pone en peligro el propósito de humanidad de la privación de libertad, desde su visión constitucional.

Supone el discurso oficial que la institucionalización de una persona es para lograr con ella una serie de acciones que facilitarán a futuro una integración positiva a la sociedad, la atención que recibirá le permitirá la crear habilidades sociales y destrezas que le permitirán integrarse al medio social sin conflicto (Sandoval 1983).

La sobrepoblación y el hacinamiento, como hemos visto, afecta la dinámica de la institución penitenciaria de forma sensible; de hecho, otro factor de derechos humanos que se ve reducido es la capacidad del sistema penitenciario de acceder a la visita de los familiares de los privados de libertad y que la persona recluida tenga la posibilidad de visitar a sus familiares o atender sus enfermedades fuera del centro penal, por ejemplo. La visita carcelaria aumenta o se triplica y las salidas a la comunidad se comportan de la misma manera, a parte del fenómeno de salidas médicas que se multiplican por tres, dadas las enfermedades producto del hacinamiento (Pres I Galles, 2001). 
Hemos mencionado los efectos cercanos de la sobrepoblación y ahora brevemente nos referiremos a la cantidad de personas que se encuentran en prisión y la capacidad que el sistema penitenciario posee para contenerlas. Como habíamos referido anteriormente, desde el 2008 y hasta al presente, la población penitenciaria empezó a crecer a tal grado que, recientemente, su número se ha duplicado y la tasa de encierro, triplicado, sin que a la fecha se logre encontrar una acción del Gobierno que pretenda disminuir este factor negativo de la inflación punitiva. A continuación, enunciamos el comportamiento de la tasa de encierro en los últimos años. Este factor de mejora en el sistema de justicia tiene como efecto negativo el crecimiento de las tasas de encierro, en particular porque se privilegia el uso de la cárcel como el único mecanismo social para resolver los conflictos sociales. Sin embargo, la sociedad costarricense no se preparó en el nivel de infraestructura penitenciaria para enfrentar un posicionamiento de mano dura contra la criminalidad.

\section{Tabla 1}

Comportamiento de las tasas de encierro en Costa Rica en los últimos años

\begin{tabular}{c|c}
\hline Año & Tasa de población penitenciaria por cada 100 mil habitantes \\
\hline 1996 & 194 \\
\hline 2006 & 209 \\
\hline 2007 & 210 \\
\hline 2008 & 218 \\
\hline 2009 & 237 \\
\hline 2010 & 265 \\
\hline 2018 & 374 \\
\hline
\end{tabular}

Fuente: Elaboración propia.

Como puede verse en la tabla 1, el proceso de crecimiento es vertiginoso y la contraparte que es la construcción penitenciaria no se comporta de la misma manera. De los informes presentados por el Ministerio de Justicia y Paz, al Ministerio de Planificación y de Hacienda de los años 2010 al 2017, se logra ver que el crecimiento en infraestructura penitenciara siempre estuvo por debajo del número de ingresos. Para el año 2017, oficialmente se dijo que se tenían 10381 espacios y se poseía una población de 13 983, o sea, había casi cuatro mil personas de más (3602).

Luego de las políticas de seguridad ciudadana promovidas durante los años 2007 a 2010, en donde se duplicó el número de policías, se amplió de manera importante el número de tribunales y hasta se crearon otros especiales como los de Flagrancia 
y, en oposición, el presupuesto para la construcción de nuevas cárceles no fue lo simbólico que fue para los otros aparatos del control social. Por consiguiente, se promovió una política de seguridad ciudadana para sacar de circulación a la mayor cantidad de personas consideradas desviadas y llevarlas a prisión, sin haber considerado adecuadamente el número de espacios carcelarios para realizar con éxito la primera decisión. A este fenómeno, se suma también una política penitenciaria oscilante entre el uso de la cárcel como el máximo instrumento del control social, a entender la cárcel como medio transitorio de prevención del delito.

Por último, se considera importante mencionar que, al aumentar el número de organismos de prevención del crimen, por efecto rebote se aumenta el número de personas detenidas y esto provoca un crecimiento del número de personas en la cárcel, por lo que la tasa de encierro se incrementa de forma creciente. La pregunta es si esto es bueno o no: para unos, los encargados de las políticas de persecución del crimen, el hecho es positivo y tiende a generar una imagen de seguridad; para otros, se criminalizan más personas, más conductas $\mathrm{y}$, por ende, se da una hiperinflación punitiva, lo que ensancha el número de personas criminalizadas, hay un aumento automático de las tasas de criminalidad y se incrementa el uso de la prisión como instrumento del control social.

A nuestro juicio, este factor es el responsable de los problemas que en la actualidad posee el Sistema Penitenciario Nacional. El Mecanismo Nacional de Prevención Contra la Tortura indicó que la sobrepoblación carcelaria rondaba el 30 \% y que esta situación provocaba tratos contrarios a los derechos humanos (La Prensa Libre, 25 junio 2018, p.10). De continuar por este camino, la sobrepoblación y el hacinamiento carcelario se tendrían que considerar un problema endémico y, por consiguiente, de salud pública. Desde el 2009, los centros penitenciarios del país dedicados a alojar hombres adultos se mantienen sobrepoblados; en el 2014 se llegó a tener una sobrepoblación del $42 \%$, para llegar en el presente a un $36 \%$. Esto significa que donde debe haber una persona ubicada existe 3,6 de más.

Otro factor interesante de investigar, pero sería para otro estudio, es el denominado problema de la ejecución presupuestaria, porque a pesar de que se cuenta con recursos económicos o financieros, estos no se ejecutan con la rigurosidad debida ante el crecimiento de la sobrepoblación y del hacinamiento carcelario. De acuerdo con los informes del Ministerio de Hacienda y de la Contraloría General de la República, los presupuestos para la construcción de infraestructura penitenciaria se vienen subejecutando desde el 2010. Este comportamiento, si lo vemos desde el contexto de los derechos humanos, es inverosímil, pues se supone que los dineros asignados por el Estado costarricense para las construcciones carcelarias 
deberían ejecutarse en su totalidad y con ello reducir el faltante de dichos espacios, lo que solventaría el alojamiento y se ampliarían los espacios para la atención, el trabajo, la educación y el esparcimiento de esa población.

Resultan contradictorias la política penitenciara y la política de persecución del crimen, cuando por efectos de equilibrio financiero del Estado no se pueden ejecutar las acciones de construcción de instalaciones penitenciarias. Este factor, junto a la complicada política de concursos para la contratación de construcciones, se confabula para hacer del problema de la sobrepoblación un hecho casi insuperable (Vargas, 2011). Y ¿qué pasa con la población penitenciaria? ¿Cuál ha sido su comportamiento en los últimos años y qué se está haciendo para controlar el crecimiento de esta? Son interrogantes a las que intentaremos redactar una respuesta, a la luz de los hechos visibles de la política penitenciaria. Como habíamos mencionado, desde el 2008 se dio un despegue en la población penitenciaria en el claustro, los ingresos anualmente venían superando con creces los egresos, fueran estos por cumplimiento de la pena, por beneficios penales o penitenciarios.

Lo cierto es que, la población empezó a crecer hasta que, en el 2016, el Sistema Penitenciario Nacional, tenía una sobrepoblación del $41 \%$ y las instalaciones penitenciarias de algunos centros rondaban $164 \%$ de ocupación. Lo paradójico de este contexto es que, al revisar la documentación producida por el Instituto Nacional de Criminología-circulares y los datos estadísticos- se mantenía vigente una política de desinstitucionalización que pretendía que grupos importantes de población que por sus características criminológicas, por el grado de ejecución de la pena o por la respuesta a los procesos de atención, tenían las condiciones para iniciar un proceso de inserción social. Este se consideraba como uno de los pilares del Sistema Penitenciario, desde el Plan de Desarrollo Institucional y hasta el documento denominado Política Penitenciara Cientifica y Humanística. Sin embargo, el ingreso de personas a la cárcel en condición de indiciadas y sentenciadas ha superado por mucho a los que se egresan, esto como producto de las políticas de desinstitucionalización y el número de sentencias que es incontrolable. De acuerdo con declaraciones dadas por los jerarcas políticos del Ministerio de Justicia y Paz, la población penitenciaria crece anualmente en un $0,7 \%$, lo significa que al menos 700 personas nuevas cada año.

Se mantiene a pesar de la argumentación anterior una posición oficial de que la prisión es la última ratio del sistema penal, pero los datos nos dicen otra cosa.

Tabla 2 
Comportamiento de la población penitenciaria institucionalizada. Desde al año 2009 al 2018.

\begin{tabular}{c|c}
\hline Año & Cantidad de privados de libertad \\
\hline 2009 & 8924 \\
\hline 2010 & 10137 \\
\hline 2011 & 11570 \\
\hline 2012 & No hay anuario \\
\hline 2013 & 13560 \\
\hline 2014 & 13771 \\
\hline 2018 & 15454 \\
\hline
\end{tabular}

Fuente: Elaboración propia por medio de consultas a los anuarios estadísticos publicados en la página del Ministerio de Justicia y Paz.

Como podemos ver el panorama carcelario no se comporta de forma positiva desde el contexto del uso de instrumentos sustitutivos a la prisión, por el contrario, pareciera verse un deseo importante por usar la cárcel como el elemento de control predilecto. La tendencia es al crecimiento de la población encarcelada y a ir disminuyendo el uso de otros instrumentos de control menos formales, desde la perspectiva de la seguridad ciudadana. El panorama no es halagüeño para aquellos que pretenden que la cárcel se deje de utilizar como la primera ratio del derecho penal, por el contario Costa Rica se ha introducido de forma gradual en el populismo punitivo y pareciera que este tiene más éxito que las posturas contrarias emanadas desde los organismos defensores del uso de otras formas de control social.

Esta contradicción la vemos más expuesta en los hechos que se generan desde la jurisdicción: por un lado, los jueces de ejecución de la pena desde el año 2014 vienen dictando resoluciones para reducir el hacinamiento y la sobrepoblación penitenciaria y por otro lado, la Sala Constitucional ha dictado sendas resoluciones que compelen a la autoridad penitenciaria a hacer lo necesario para reducir la sobrepoblación o dicho hacinamiento. Sin embargo, la Sala Constitucional también resuelve en el 2018 la necesidad de que el Sistema Penitenciario en el término de 48 horas reciba la totalidad de las personas que se encuentran detenidas en las celdas del Organismo de Investigación Judicial o da instrucciones para que, en el corto plazo, se construyan nuevas cárceles sin dar los instrumentos políticos o de política fiscal para lograr los fondos para su construcción. De nuevo existe una posición oscilante en cuanto a qué hacer con la sobrepoblación y el hacinamiento carcelario versus las políticas de seguridad ciudadana. 
Para los efectos de este documento queda demostrado que existen dos caras de la moneda en temas de sobrepoblación, hacinamiento y derechos humanos, por encima del deseo de restringir el uso de la cárcel como instrumento de control social, prevención del delito y seguridad pública, prevalece el concepto de seguridad ciudadana y el encierro como el factor catalítico de estas posiciones.

\section{A manera de conclusión}

Queda claro que el fenómeno social del delito y la utilización de la cárcel como instrumento disuasorio, tiene en nuestros días un éxito importante. Sí es válido rescatar que la cárcel puede mantenerse hoy día como el lugar escogido para que los transgresores de la ley ejecuten sus sentencias, pero que las condiciones de esta no puede contravenir la ley y los principios de humanidad. Esta situación de protección de los intereses de la persona recluida está en manos de organismos no vinculados al ejercicio del castigo, por lo que sus recomendaciones son consideradas y con pocas posibilidades de ser atendidas en su totalidad. Desde hace ya varios años los jueces de ejecución de la pena y la misma Sala Constitucional vienen marcándole cierto territorio de cuidado al Sistema Penitenciario Nacional y a la fecha muy pocas de las recomendaciones dadas se han logrado cumplir.

Es evidente esta afirmación cuando se revisan los informes anuales del Mecanismo Nacional Contra la Tortura (Defensoría de los Habitantes), en donde se evalúan las condiciones de supervivencia de la población penitenciara, las afectaciones son las mismas de años: deterioro de los servicios de alimentación, deterioro de los servicios de salud, deterioro de las condiciones de vida por la sobrepoblación y el hacinamiento, en consonancia con las "medidas correctivas" emitidas por los jueces de ejecución de la pena, violatorias de los principios de derechos humanos.

Si se imita la postura de quienes consideran que el derecho penal por sí solo no resuelve la delincuencia, ni los conflictos sociales y se sigue a los teóricos de la Teoría del Conflicto Social, se agrava la situación de la persona presa al dejar a la familia sin el sostén económico. En el plano social se encarcela a la población económicamente activa.

En el caso de Costa Rica, al menos un $65 \%$ de los privados de libertad se encuentran entre los 18 y 40 años de edad, circunstancia que hace visible que se deben de buscar otros instrumentos jurídicos para controlar al denominado delincuente. También la familia como centro de producción de recursos vinculares se ve afectada al separar a sus componentes y al eliminar la posibilidad de que se desarrollen relaciones familiares sanas. Además, el encarcelamiento produce la 
traslación de la pena a los familiares de las personas privadas de libertad, sin que estos se encuentren relacionados con el delito.

Este factor que se ha trabajado en la literatura criminológica de forma somera es un elemento psicológico que vulnera las relaciones vinculares, al someter a una de las partes (la no culpable) a las prácticas de seguridad y vigilancia de la cárcel. Para mantener el vínculo, la persona de afuera debe someterse a los procedimientos de registro, de identificación y de señalamiento social que produce el ser visitante de un establecimiento penitenciario.

Por otro lado, la denominada Política Criminal del país -si esta existe- está enfocada en la ejecución de mega operativos policiales para detener y sacar de circulación a aquellas personas que por diferentes motivos se encuentran morosos con la justicia o que parezcan sospechosos de alguna ilicitud, razón por la cual el hacinamiento carcelario será creciente en el futuro y la infraestructura penitenciaria deficitaria. Esto incrementará la violación de derechos humanos y la cárcel llegará a transformarse en una incubadora de violencia y de delincuencia.

Se propone reducir los efectos del uso de la cárcel para mejorar la calidad de vida de las personas que se encuentran en reclusión:

- Se deben construir nuevas prisiones, las cuales deben estar avitualladas de tecnología, de condiciones de habitabilidad suficientes.

- Se debería exponer una política institucional y de política criminal que establezca que cuando la población alcance números cercanos a la sobrepoblación (no más del $20 \%$ ) se inicie un programa de ubicaciones en otros centros menos cerrados de aquella población, que tenga al menos la mitad de la pena descontada y que las criminalidades que posean no estén relacionadas con delincuencias del crimen organizado y que, además, sus procesos de atención se encuentren finalizados y que los informes de los profesionales encargados de la atención hayan manifestado su complacencia con los resultados obtenidos.

- Para dichas ubicaciones, se debería contar con la anuencia de los Juzgados de Ejecución de la Pena, de la defensa Pública de la Ejecución de la Pena y de su contraparte la Fiscalía de Ejecución Penal. Con esta fórmula de entenderían las necesidades de víctima y del derecho penal en su conjunto.

- Es evidente que para lograr esta propuesta se necesitan instrumentos de coordinación entre las partes operantes en la política penitenciaria y criminal, que deberían respaldarse por decisiones del Poder Judicial y del Poder Ejecutivo, en donde el encargado de gestionar el Ministerio de Justicia y Paz sería el líder de la acción. 
- También es necesaria la promoción de un proyecto de Ley de Ejecución Penal para la persona adulta sentenciada, con una orientación de humanidad y de respeto hacia la persona privada de libertad.

\section{Referencias}

Aguilar Herrera, G. (2011). Ejecución de la pena, historia, límites y control jurisdiccional. San José, Poder Judicial, Defensa Pública.

Carranza Lucero, E. (2003). Defensa Pública y Personas Presas en América Latina. Revista Defensa Pública. 247-255.

García Pablos de Molina, A. (2005). Tratado de Criminología. España: Editorial Tirant le Blanc

Hulsman, L y Bernart de Celis, J. (1984). Sistema penal y seguridad ciudadana hacia una alternativa. Barcelona, España: Editorial Ariel.

Madrigal, Zamora, R. (2012). El papel de tonto de los mecanismos nacionales de protección frente al fenómeno del hacinamiento carcelario. Revista Digital de la Maestría en Ciencias Penales, (4), 404-466.

Ministerio de Justicia y Gracia. (1993). Plan Nacional de Desarrollo, Registro Nacional, San José, Costa Rica.

Ministerio de Justicia y Paz. Memorias de labores de labores del año 2009 al 2016. San José.

Ministerio de Justicia y Paz. (2018). Política penitenciaria cientifica y humanista. San José, ICD.

Murillo Rodríguez, R. (2012). Populismo Punitivo, cárcel perpetúa y hacinamiento crítico en Costa Rica, más inseguridad por menos libertad. Reflexiones Jurídicas frente al Populismo Penal en Costa Rica. San José, Costa Rica, 283-300.

Pares i Galles, R. (2001). Efectos de la sobrepoblación penitenciaria en Cataluña. Justicia penal y sobrepoblación penitenciaria. México: Editorial Siglo XXI. Robles Escobar, O. (2012). El hacinamiento carcelario y sus consecuencias. Revista Digital de la Maestría en Ciencias penales, (3), 405- 431.

Sánchez Romero, C. (2018). Aciertos y desafios de los Sistemas Penitenciarios en América Latina desde una perspectiva de Derechos Humanos. Ponencia para Congreso de Criminología en la Ciudad de Guanajuato, México. 
Sánchez Ureña, H. (2011). Las reformas al Código Penal y sus consecuencias en las prisiones: El caso de Costa Rica. Revista Digital de la Maestría en Derecho Penal, (3), 433-455.

Sandoval Huertas, E. (1983). Penología. Parte Especial. Colombia. Universidad Externado Colombia.

Tidball-Binz, M. (2001). Atención de la salud y sobrepoblación penitenciaria. Un problema de todos. En: Justicia Penal y Sobrepoblación penitenciaria. México: Editorial Siglo XXI.

Ramírez Vargas, E. (2011). Derechos humanos y sobrepoblación penitenciaria en Costa Rica: periodo 2008 a 2010 (tesis de maestría). Universidad Estatal a Distancia. Costa Rica.

Zaffaroni, E. (1990). La filosofía del sistema penitenciario en el mundo contemporáneo. Conferencia Especial, seminario regional para Directores de centros penitenciarios y de detención en América Latina. Cruz Roja Internacional, ILANUD, IIDH, San José.

Wacquant, L. (2010). Castigar a los pobres. Barcelona, España: Editorial GEDISA 
